\title{
The effect of self-management program on perceived social support of family caregivers of stroke patients
}

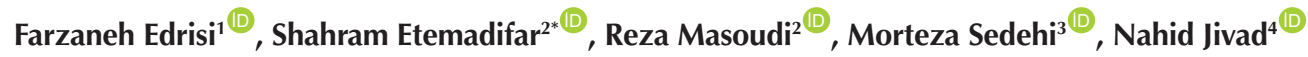 \\ ${ }^{1} \mathrm{MSc}$ Student on Nursing, Shahrekord University of Medical Sciences, Shahrekord, Iran \\ ${ }^{2}$ Associate Professor, Community-Oriented Nursing Midwifery Research center, Nursing and midwifery school, Shahrekord \\ University of Medical Sciences, Shahrekord, Iran \\ ${ }^{3}$ Associate Professor, Department of Epidemiology and Biostatistics, School of Health, Shahrekord University of Medical \\ Sciences, Shahrekord, Iran \\ ${ }^{4}$ Assistant Professor, Department of Neurology, School of Medicine, Shahrekord University of Medical Sciences, Shahrekord, Iran
}

\begin{abstract}
Background and aims: Stroke is the first leading cause of disability in adults. Long-term disability after stroke necessitates long-term caregiving by family members. The family caregivers (FCGs) of patients with stroke (PWS) experience different problems and hence, require self-management (SM) skills. The aim of this study was to assess the effects of an SM program based on Strauss and Corbin's SM model on perceived social support (PSS) among the FCGs of PWS.

Methods: This quasi-experimental study was conducted in 2019-2020. Participants were eighty FCGs of PWS who were hospitalized in Kashani hospital, Shahrekord, Iran. They were purposefully- recruited and randomly allocated to a control and an intervention group. An SM program based on Strauss and Corbin's SM model was implemented in six ninety-minute sessions for participants in the intervention group. The Multidimensional Scale of PSS was used for PSS assessment before, immediately after, and two months after the intervention. Data were analyzed using the SPSS software (v. 16.0).

Results: There was no significant difference between the groups in terms of the pretest mean score of PSS $(P=0.76)$, while the mean score of PSS in the intervention group was significantly greater than the control group at both posttests $(P<0.05)$. Moreover, the mean score of PSS in the control group did not significantly change across the three measurement time points $(P>0.05)$, but significantly increased in the intervention group $(P<0.05)$.

Conclusion: SM program based on Strauss and Corbin's SM model is effective in significantly improving PSS among the FCGs of PWS. Therefore, nurses and other healthcare providers can use this program for the FCGs of PWS.

Keywords: Stroke, Family caregivers, Self-management, Perceived social support
\end{abstract}

*Corresponding Author: Shahram Etemadifar

Email: sh.etemadifar@yahoo. com

\section{Introduction}

Stroke is the second leading cause of death with a death rate of $11.3 \%$ and the first leading cause of disability among adults in the world (1). The prevalence of stroke is predicted to increase with the growing increase of the population of people over sixty which is estimated to double by 2050 and triple by 2100 (2).

Almost $50 \%$ of patients with stroke (PWS) suffer from permanent problems in balance, standing, and walking, as well as disability in doing the activities of daily living such as changing clothes, eating, and bathing (3). Therefore, family caregivers (FCGs) play significant role in caregiving to PWS. As stroke occurs suddenly, family members of PWS should assume caregiving responsibility without adequate preparation (4).

Caregivers are individuals who are mostly involved in caregiving to patients in the course of a disease or disability in order to help them cope with or manage their conditions. There are two main types of caregivers, namely formal and informal. Formal caregivers are trained caregivers, have professional competencies for delivering different care services, and receive payment for their services. However, informal caregivers, including spouses, children, and friends, may not receive regular payment (5). The role of caregivers is more important when PWS need long-term care (6). Currently, PWS have short hospital stay due to the heavy costs of hospital services and hence, the major part of caregiving to these patients is with their FCGs (7).

During caregiving, FCGs usually face different physical, psychological, and social challenges which predispose them to physical and mental health problems (such as depression and anxiety), financial problems, social isolation, role conflicts, change of goals, and low quality of life (8). Most FCGs report caregiving problems and low quality of life due to limited social and financial support, lack of educational programs, exposure to their patients' physical and mental problems, and limited access to rehabilitation services for their patients (9). Therefore, support systems in societies need to assess their needs and take appropriate measures to provide

(C) 2021 The Author(s); Published by Shahrekord University of Medical Sciences. This is an open-access article distributed under the terms of the Creative Commons Attribution License (http://creativecommons.org/licenses/by/4.0), which permits unrestricted use, distribution, and reproduction in any medium, provided the original work is properly cited. 
them with adequate help and support (10). Social support is associated with different positive outcomes, such as improved self-confidence, sense of competence and productivity, and better quality of life, while limited social support is associated with mental problems and poor health status (11). As an emotion-focused coping strategy, social support can prevent the occurrence of stressful conditions, and thereby, protects individuals and helps them evaluate and manage stressful conditions to reduce their effects (12).

There are two main types of social support, namely received social support and perceived social support (PSS). Received social support refers to the amount of received support, while PSS refers to individuals' perceptions of the availability of support in emergencies. PSS is measurable and is a criterion for self-evaluation (13). Compared with received social support, PSS has more important role in reducing psychological strains (14). PSS can reduce the problems of FCGs, particularly the FCGs of patients with chronic conditions. Moreover, adequate PSS among FCGs has positive effects on patient outcomes. A study reported that limited social and informational support for FCGs was associated with problems in caregiving to PWS and adherence to rehabilitation programs (15). Another study showed that family education and support positively affected patients' self-efficacy and self-management (SM) (16).

SM is a factor with potential effects on PSS among the FCGs of PWS. SM plays significant role in empowering individuals to manage their personal and organizational behaviors, improve their productivity, and modify their lifestyle (17). SM is a dynamic and ongoing interactive process which helps individuals reinforce a positive behavior or skill or reduce the incidence of an inappropriate behavior. Successful SM is associated with greater sense of responsibility towards personal behaviors and greater senses of control and self-efficacy (18). The core of SM is an individual who wants to start SM and extend it to society (19). SM skills include problem solving, decision making, using resources, therapeutic relationship with healthcare providers, and taking action (20). Chronic disease SM was first introduced by Anselm Strauss and Juliet Corbin. They noted that chronic disease SM is based on knowledge and skills for several sets of assignments. The first set of assignments pertains to the medical management of disease and pain and includes regular medical visits, appropriate use of medications, awareness of medical treatments, and adherence to dietary regimen. The second set of assignments pertains to the management of roles and daily activities such as interaction with friends and family members, occupational activities, and habits. The third set of assignments pertains to the management of the emotional consequences of affliction by a chronic disease such as depression and anxiety (21). A study reported that the implementation of SM program was associated with stronger social support for the FCGs of PWS (22).

To the best of our knowledge, most previous studies into the effects of SM interventions on perceived support were conducted on patients and hence, there is limited information about the effects of such interventions on the FCGs of PWS (23). Therefore, further studies are needed to narrow this gap. The present study aimed at assessing the effects of an SM program based on Strauss and Corbin's SM model on PSS among the FCGs of PWS.

\section{Methods}

Design

This two-group quasi-experimental study was conducted in an eight-month period from September 2019 to May 2020.

\section{Participants and setting}

Study population consisted of the FCGs of PWS whose patients were hospitalized in Kashani hospital, Shahrekord, Iran. Eligibility criteria were an age of 18-65 years, ability to read and speak Persian, significant role in caregiving, close kinship with patient, and receiving no payment for caregiving. Exclusion criteria were irregular participation in the intervention sessions and patient death during the study.

Based on the findings of previous studies $(16,20,22)$ sample size was determined to be 35 FCGs per group. Nonetheless, sample size was expanded to forty per group in order to compensate probable withdrawals from the study. Participants were purposefully selected and randomly allocated to a control and an intervention group through a table of random numbers.

\section{Intervention}

Participants in the intervention group received SM program based on Strauss and Corbin's model in six ninety-minute sessions. Table 1 shows the details of the program. Participants in the control group did not receive any SM intervention. PSS was assessed in both groups before, immediately after, and two months after the intervention.

\section{Instrument}

PSS was assessed using the twelve-item Multidimensional Scale of PSS. Zimet et al introduced this instrument in 1988 for assessing PSS by family members (4 items), friends (4 items), and significant others (4 items). The items of this scale are scored on a five-point Likert scale from 1 to $5(24,25)$, resulting in a possible total score of 12-60. The total score of this sale is interpreted as follows: scores 12-20: limited PSS; scores 20-40: moderate PSS; and scores 40-60: strong PSS. A former study in Iran confirmed the validity and reliability of this scale through respectively the factor analysis and internal consistency methods and reported that the Cronbach's alpha values of its dimensions were $0.86,0.86$, and 0.82 , respectively (26). Another study in Iran reported that the Cronbach's alpha values of the dimensions of this scale were 0.76-0.89 (27). 
Table 1. The content of SM program

\begin{tabular}{|c|c|c|}
\hline Session & Content & Teaching methods \\
\hline 1 & $\begin{array}{l}\text { Introduction of participants to each other; Explanations about the study aims and rules; Explanations about stroke; } \\
\text { Explanations about SM and its effects; Pretest }\end{array}$ & $\begin{array}{l}\text { Lecture } \\
\text { PowerPoint presentation } \\
\text { Question and answering }\end{array}$ \\
\hline 2 & $\begin{array}{l}\text { Assessment of caregiving-related problems; Expression of the positive and negative experiences of caregiving; } \\
\text { Explanations about how to manage caregiving-related problems; Explanations about how to use problem solving and } \\
\text { decision making skills }\end{array}$ & $\begin{array}{l}\text { Lecture } \\
\text { Group discussion }\end{array}$ \\
\hline 3 & $\begin{array}{l}\text { SM for stroke and pain; Explanations about vital signs; Explanations about communication with PWS, particularly } \\
\text { those with aphasia; Explanations about the necessary measures in case of the aggravation of patient's conditions; } \\
\text { Explanations about appropriate medication use and warning signs; Explanations about the importance of caregiver's } \\
\text { physical pain and healthy eating; Explanations about the symptoms of stress and depression }\end{array}$ & $\begin{array}{l}\text { Lecture } \\
\text { Group discussion } \\
\text { Role playing } \\
\text { Counseling }\end{array}$ \\
\hline 4 & $\begin{array}{l}\text { Explanations about the SM of roles and daily activities such as communication with other family members and friends } \\
\text { and receiving their support, avoidance from loneliness, importance of adequate sleep, consideration of leisure and } \\
\text { recreational activities in order to reduce fatigue (such as short travels), and consideration of wok-life balance }\end{array}$ & $\begin{array}{l}\text { Lecture } \\
\text { Group discussion } \\
\text { Role playing } \\
\text { Counseling } \\
\text { Brainstorming }\end{array}$ \\
\hline 5 & $\begin{array}{l}\text { Explanations about emotion management, communication with healthcare providers to talk about patients' } \\
\text { problems, sharing feelings, positive thinking, praying and thanks giving to God, engagement in favorite activities, and } \\
\text { consideration of spirituality }\end{array}$ & $\begin{array}{l}\text { Lecture } \\
\text { Group discussion }\end{array}$ \\
\hline 6 & $\begin{array}{l}\text { Summarizing the content of previous sessions; Provision of an educational booklet; Answering questions and } \\
\text { clarifying ambiguities; Posttest }\end{array}$ & $\begin{array}{l}\text { Lecture } \\
\text { Question and answering }\end{array}$ \\
\hline
\end{tabular}

\section{Results}

Age mean was 43.37 years in the intervention group and 44.22 years in the control group. Most participants in these groups were female (65\% vs. $57.5 \%)$, married $(85 \%$ vs. $90 \%$ ), and employed (65\% vs. $55 \%$ ). Moreover, $37.5 \%$ of participants in the intervention group and $47.5 \%$ of participants in the control group had secondary diploma. There were no significant differences between the groups in terms of participants' gender, marital status, employment status, and educational level $(P>0.05$; Table 2$)$.

The repeated measures analysis of variance showed that in the control group, the mean score of PSS did not significantly change across the three measurement time points $(P>0.05)$, while this mean score significantly increased in the intervention group $(P<0.05)$. The independent-sample $t$ test indicated no significant difference between the groups regarding the pretest mean score of PSS $(P=0.76)$. However, the mean score of PSS in the intervention group was significantly greater than the control group at both posttests $(P<0.05)$ (Table 3$)$.

\section{Discussion}

Most participants of the study were married (85\% in the intervention group and $90 \%$ in the control group). This is in line with the findings of several previous studies (28$30)$. Moreover, most participants were female (65\% in the intervention group and $57.5 \%$ in the control group). Several former studies also reported that most FCGs were female (9,29,31). In addition, a large percent of participants had secondary diploma (37.5\% in the intervention group and $47.5 \%$ in the control group). This agrees with the findings of a former study (32).

Study findings revealed that the mean score of PSS in the intervention group significantly increased after the implementation of the SM program. A previous study also found the positive effects of rehabilitation services on PSS and caregiver burden among the caregivers of PWS (33). Another comparative study into the effects of
Table 2. Between-group comparisons respecting participants' characteristics

\begin{tabular}{|c|c|c|c|c|c|c|}
\hline \multirow{3}{*}{ Characteristics } & & \multicolumn{4}{|c|}{ Groups } & \multirow{3}{*}{$\begin{array}{c}P \\
\text { value }^{a}\end{array}$} \\
\hline & & \multicolumn{2}{|c|}{ Intervention } & \multicolumn{2}{|c|}{ Control } & \\
\hline & & No. & $\%$ & No. & $\%$ & \\
\hline \multirow{3}{*}{$\begin{array}{l}\text { Employment } \\
\text { status }\end{array}$} & Employed & 26 & 65 & 22 & 55 & \multirow{3}{*}{0.30} \\
\hline & Housewife & 10 & 25 & 16 & 40 & \\
\hline & Retired & 4 & 10 & 2 & 5 & \\
\hline \multirow{2}{*}{ Marital status } & Married & 34 & 85 & 36 & 90 & \multirow{2}{*}{0.50} \\
\hline & Single & 6 & 15 & 4 & 10 & \\
\hline \multirow{2}{*}{ Gender } & Female & 26 & 65 & 23 & 57.5 & \multirow{2}{*}{0.49} \\
\hline & Male & 14 & 35 & 17 & 42.5 & \\
\hline
\end{tabular}

a The results of the chi-square test.

Table 3. Within- and between-group differences regarding the mean score of perceived social support

\begin{tabular}{|c|c|c|c|}
\hline \multirow{3}{*}{ Time } & \multicolumn{2}{|c|}{ Groups } & \multirow{3}{*}{$P$ value $^{a}$} \\
\hline & Intervention & Control & \\
\hline & Mean \pm SD & Mean \pm SD & \\
\hline Before & $39.10 \pm 11.04$ & $39.75 \pm 7.37$ & 0.76 \\
\hline Immediately after & $9.68 \pm 43.52$ & $7.38 \pm 40.25$ & 0.045 \\
\hline Two months after & $9.10 \pm 45.32$ & $7.50 \pm 39.55$ & 0.003 \\
\hline$P$ value ${ }^{b}$ & $<0.05$ & $<0.05$ & - \\
\hline
\end{tabular}

a The results of the independent-sample $t$ test; ${ }^{\mathrm{b}}$ The results of the repeated measures analysis of variance.

an SM program and a standard educational program also revealed that the SM program was associated with higher PSS among FCGs of PWS (22). Similarly, a study reported that group and family support helped maintain the level of PSS among the FCGs of PWS (34). A study on the FCGs of patients with dementia also showed the positive effects of SM on PSS (35). Moreover, a study found that health education programs significantly improved social health among the FCGs of PWS (36). PSS among the FCGs of patients with epilepsy and PWS has significant direct relationships with their SM ability, quality of life (35), and mental health (37). 
What does this paper contribute to the wider global clinical community?

SM program can reduce the negative outcomes of caregiving and improve caregiving knowledge among the FCGs of PWS.

\section{Conclusion}

This study concludes that the SM program based on Strauss and Corbin's SM model is effective in significantly improving PSS among the FCGs of PWS. Higher levels of PSS among these FCGs can improve their ability to more effectively perform their roles and manage their problems. Given the effectiveness and simplicity of the SM program, nurses are recommended to use it for improving PSS among FCGs.

\section{Acknowledgement}

This article was extracted from the first author's Master's thesis in Medical-Surgical nursing. We would like to thank the Research Administration of Shahrekord University of Medical Sciences, Shahrekord, Iran, the authorities of Kashani hospital, Shahrekord, Iran, and PWS and their FCGs who collaborated with us in this study.

\section{Conflict of Interests}

None declared.

\section{Ethical Approval}

The thesis was approved by the Ethics Committee of Shahrekord University of Medical Sciences, Shahrekord, Iran (code: IR.SKUMS. REC.1398.176).

\section{References}

1. Mozaffarian D, Benjamin EJ, Go AS, Arnett DK, Blaha MJ, Cushman $M$, et al. Executive summary: heart disease and stroke statistics-2015 update: a report from the American Heart Association. Circulation. 2015; 131(4):434-41. doi: doi:10.1161/cir.0000000000000157.

2. Sanuade OA, Dodoo FN, Koram K, de-Graft Aikins A. Prevalence and correlates of stroke among older adults in Ghana: evidence from the Study on Global AGEing and adult health (SAGE). PLoS One. 2019; 14(3):e0212623. doi: 10.1371/journal.pone.0212623.

3. Khorrami-Markani A, Yarmohammadi A, Khalkhali HR, Azimzadeh R. Assessing the effectiveness of home nursing care plan on activities of daily living of stroke patients in Urmia city, 2014. J Urmia Nurs Midwifery Fac. 2016; 13(12):107180. [Persian].

4. Lutz BJ, Young ME. Rethinking intervention strategies in stroke family caregiving. Rehabil Nurs. 2010; 35(4):152-60. doi: 10.1002/j.2048-7940.2010.tb00041.x.

5. Aboozadeh Gotabi K, Ghanbari Moghaddam A, Mohammadi $M$, Zarei F. The burden of family caregivers caring for older adults and its relationship with some factors. Nursing of the Vulnerable Journal. 2016; 3(6):27-36. [Persian].

6. Tajvidi M, Dalvandi A, Sahaf R, Rahgozar M. Relationship between general health and demographic characteristics of family caregivers of stroke survivors. Iran J Ageing. 2018; 12(4):494-505. doi: 10.21859/sija.12.4.494. [Persian].

7. Sit JW, Wong TK, Clinton M, Li LS, Fong YM. Stroke care in the home: the impact of social support on the general health of family caregivers. J Clin Nurs. 2004; 13(7):816-24. doi: 10.1111/j.1365-2702.2004.00943.x.

8. Chen P, Fyffe DC, Hreha K. Informal caregivers' burden and stress in caring for stroke survivors with spatial neglect: an exploratory mixed-method study. Top Stroke Rehabil. 2017; 24(1):24-33. doi: 10.1080/10749357.2016.1186373.

9. Jung BC, Kim HJ. The effect of rehabilitation education program on family caregivers of stroke patients. Sci J Public Health. 2014; 2(4):337-41.

10. Koohestani HR, Baghcheghi N. Burn out in caregivers of patients with stroke and its related factors. Hakim Res J. 2012; 14(4):242-8. [Persian].

11. Javadifar N, Larki A, Javadnoori M, Haghighizadeh MH. The relationship between perceived social support and lifestyle in middle-aged females of Ahvaz, Iran. Jundishapur J Chronic Dis Care. 2017; 6(1):e37111. doi: 10.17795/jjcdc-37111.

12. Nourbakhsh $\mathrm{Y}$, Heidarkhani $\mathrm{H}$, Mohammadi A. Investigating the relationship between social support and underlying variables with social health of young people in marginalized areas of Kermanshah. Journal of Social Problems of Iran. 2018; 8(2):233-57. [Persian]

13. Gülaçtı F. The effect of perceived social support on subjective well-being. Procedia Soc Behav Sci. 2010; 2(2):3844-9. doi: 10.1016/j.sbspro.2010.03.602.

14. Wethington E, Kessler RC. Perceived support, received support, and adjustment to stressful life events. J Health Soc Behav. 1986; 27(1):78-89.

15. Bavazin F, Sepahvandi MA. The study of the relationship between social support and psychological well-being among elderly people in city of Khorramabad in 2017. J Urmia Nurs Midwifery Fac. 2019; 15(12):931-8. [Persian].

16. Amini Moridani M, Tol A, Sadeghi R, Mohebbi B, Azam K. Assessing the effect of family-based intervention education program on perceived social support among older adults with type 2 diabetes: application of social cognitive theory. J Nurs Educ. 2015; 4(3):30-40. [Persian].

17. Ashktorab T, Yadollahi S, Safavi Bayat Z, Zayery F. The correlation between self-management behaviors and drug adherence among people with epilepsy in Iran Epilepsy Association. Avicenna J Nurs Midwifery Care. 2013; 21(2):515. [Persian].

18. Cramm JM, Hartgerink JM, de Vreede PL, Bakker TJ, Steyerberg EW, Mackenbach JP, et al. The relationship between older adults' self-management abilities, well-being and depression. Eur J Ageing. 2012; 9(4):353-60. doi: 10.1007/s10433-0120237-5.

19. Nazari R, Anvari M, Abudarda Z. The role of mental strength on management skills, self-management and efficiently performance sport managers. Organizational Behavior Management in Sport Studies. 2018; 5(2):57-67. [Persian].

20. Lorig KR, Holman H. Self-management education: history, definition, outcomes, and mechanisms. Ann Behav Med. 2003; 26(1):1-7. doi: 10.1207/s15324796abm2601_01.

21. Corbin JM, Strauss A. A nursing model for chronic illness management based upon the Trajectory Framework. Sch Inq Nurs Pract. 1991; 5(3):155-74.

22. Huijbregts MP, Myers AM, Streiner D, Teasell R. Implementation, process, and preliminary outcome evaluation of two community programs for persons with stroke and their care partners. Top Stroke Rehabil. 2008; 15(5):503-20. doi: 10.1310/tsr1505-503.

23. Hewitt M, Rowland JH. Mental health service use among adult cancer survivors: analyses of the National Health Interview Survey. J Clin Oncol. 2002; 20(23):4581-90. doi: 10.1200/ jco.2002.03.077.

24. Bakhtiyari $M$, Emaminaeini $M$, Hatami $H$, Khodakarim $S$, Sahaf R. Depression and perceived social support in the elderly. Iran J Ageing. 2017; 12(2):192-207. doi: 10.21859/ sija-1202192. [Persian].

25. Zimet GD, Dahlem NW, Zimet SG, Farley GK. The multidimensional scale of perceived social support.J Pers Assess. 
1988; 52(1):30-41. doi: 10.1207/s15327752jpa5201_2.

26. Salimi A, Joukar B, Nikpour R. Internet and communication: perceived social support and loneliness as antecedent variables. Psychological Studies. 2009; 5(3):81-102. [Persian].

27. Rostami R, Shahmohamadi K, Ghaedi G, Besharat MA, Akbari Zardkhaneh S, Nosratabadi M. Relations among selfefficacy, emotional intelligence and perceived social support in university students. Horizon Med Sci. 2010; 16(3):46-54. [Persian].

28. Rahmani Anaraki H, Mahmoodi GR, Rouhi G, Asayesh H, Nasiri H, Rakhshani H. General health status of neurologic patients' caregivers and the related factors. J Res Dev Nurs Midwifery. 2013; 9(2):49-55. [Persian].

29. Tosun ZK, Temel M. Burden of caregiving for stroke patients and the role of social support among family members: an assessment through home visits. Int J Caring Sci. 2017; 10(3):1696-704.

30. Masoodi R, Alhani F, Moghadassi J, Ghorbani M. The effect of family-centered empowerment model on skill, attitude, and knowledge of multiple sclerosis caregivers. J Birjand Univ Med Sci. 2010; 17(2):87-97. [Persian].

31. Dehghan Nayeri N, Mohammadi S, Pedram Razi S, Kazemnejad A. Adherence of family caregivers of patients with stroke to rehabilitation regimen. Hayat. 2012; 18(1):3041. [Persian].

32. Kheirollahi N, Khatiban M, Oshvandi K, Alhani F, Faradmal J. The effect of family-centered empowerment intervention on perceived severity of threat in caregivers of patients with stroke: a semi experimental study. Avicenna J Nurs Midwifery Care. 2014; 22(3):74-82. [Persian].

33. Karahan AY, Kucuksen S, Yilmaz H, Salli A, Gungor T, Sahin M. Effects of rehabilitation services on anxiety, depression, care-giving burden and perceived social support of stroke caregivers. Acta Medica (Hradec Kralove). 2014; 57(2):68-72. doi: 10.14712/18059694.2014.42.

34. van den Heuvel ET, Witte LP, Stewart RE, Schure LM, Sanderman R, Meyboom-de Jong B. Long-term effects of a group support program and an individual support program for informal caregivers of stroke patients: which caregivers benefit the most? Patient Educ Couns. 2002; 47(4):291-9. doi: 10.1016/s0738-3991(01)00230-0.

35. Mousavi SK, Kamali M, Azizkhani H. The effect of patient education and nurse-led telephone follow-up (tele nursing) on quality of life in patients with epilepsy. J Nurs Educ. 2020; 9(4):62-71. [Persian].

36. Wang J, Liu J, Li L, Man J, Yue S, Liu Z. Effect of education and muscle relaxation program on anxiety, depression and care burden in caregivers of acute stroke survivors: a randomized, controlled study. Medicine (Baltimore). 2021; 100(4):e24154. doi: 10.1097/md.0000000000024154.

37. Alquwez N, Alshahrani AM. Influence of spiritual coping and social support on the mental health and quality of life of the Saudi informal caregivers of patients with stroke. J Relig Health. 2021; 60(2):787-803. doi: 10.1007/s10943-02001081-w. 